\title{
Assessment of Carrying Capacity of Tourist Destinations in Dakshina Kannada District, Karnataka
}

Tiriveedhi Dileep Kumar* and Hatkar Sathish Kumar†

\begin{abstract}
In recent times, tourism has emerged as one of the most popular economic activities. In view of the economic production of Dakshina Kannada District, tourism plays a vital role. Dakshina Kannada District boasts of various activities like beach tourism, cultural, religious, education, and eco-tourism. Though enriched with tourism resources, this region has not utilised them enough to convert them into economic resources. This research is done to understand and find out the carrying capacity of tourist destinations in Dakshina Kannada District that will help us make tourism plans and strategic development activities so as to make the most of the resources available.
\end{abstract}

Keywords: Tourism Plan, Carrying Capacity, Economic Production

\section{Introduction}

Over the past few decades, tourism has been seen emerging around the world. It has become an important aspect for the growing economies in the world. There are many cities and countries whose economy is completely dependent on tourism. This increasing tourism leads to an increase in the number of arrivals to

\footnotetext{
* School of Planning and Architecture, Vijayawada, India; tiriveedhidileepkumar@gmail.com † School of Planning and Architecture, Vijayawada, India; sathish.hatkar@gmail.com.
} 
destinations. Though it has a positive impact on the destinations and their economies, it negatively affects its environment (Nghi, 2007).

The carrying capacity can assess the impact of tourism on tourist destinations. The assessment of carrying capacity of a destination measures the threshold over which the arrival of tourists can have a negative impact on the destination. The carrying capacity gives an average threshold of the number of visitors who can be accommodated in a destination at a given time (Pazienza, n.d.). Therefore, tourism carrying capacity becomes one of the important indicators used to promote sustainable tourism (Manning, 2002).

According to World Tourism Organisation, Tourism carrying capacity is defined as "the maximum number of persons who could visit a location within a given period, such that the local environmental, physical, economic, and socio-cultural characteristics are not compromised, and without reducing tourist satisfaction" (WTO, 1999). Thus, the definitions of carrying capacity of a destination explain the quantitative carrying capacity assessment by defining the number of tourists who represents the limit within which any type of degradation will not occur (Turner, 1997).

\section{Case Area Profile}

"Dakshina Kannada (erstwhile) South Kanara is one of the three coastal districts of the Karnataka state with a geographical area of 4859 sq. $\mathrm{km}$. The district lies in the vicinity of 12.570 and $13.50^{\circ}$ North Latitudes and $74^{\circ}$ and $75.50^{\circ}$ East Longitudes. It is situated between the lower regions of the Western Ghats in the east and the Arabian Sea to the west, flanked by the Udipi District towards the north, Chikkmagaluru district towards the north east, Hassan District to the east, Kodagu District to the southeast, and Kasaragod District in Kerala to the south. The district has five talukas specifically, Bantwal, Belthangady, Mangaluru, Puttur and Sulya. The Mangaluru city is the principal city in the region. It is also among the major port towns in the Karnataka state. The region is honoured with inexhaustible precipitation, prolific soil, and rich vegetation. Unblemished shorelines, beautiful mountain ranges, 
sanctuary towns, and rich culture make it a sought after travellers' goal" (Shetty, 2014).

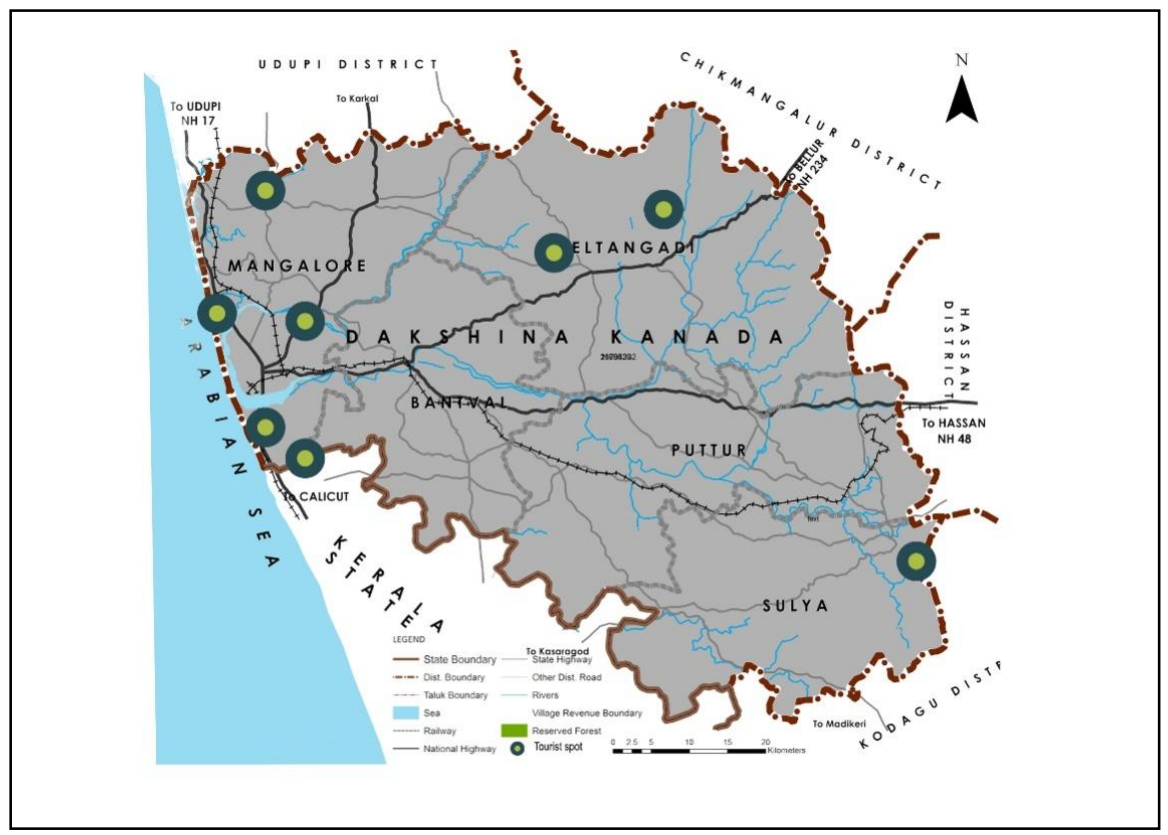

Fig 1 Tourist destinations in Dakshina Kannada District

\section{Literature and Methodology}

Coccossis (2004) argues that the term carrying capacity "derives from the wildlife environment, as it was used to define the maximal population size of animal varieties that a region can bolster without lessening its capacity to support similar number of species later on. It arouses from the perception that tourism cannot develop forever in a place without causing irreversible damage to the local system". Since the 1970s, carrying capacity has been additionally developed as a precise technique of numerical estimation for determining land-use limits and development control for overseeing tourism in sensitive natural and cultural environments (Clark, 1996).

According to Attallah (2015) "for nature-based destinations there are two types of carrying capacity that can be assessed, namely Physical Carrying Capacity (PCC) and Real Carrying Capacity (RCC)". These carrying capacities can be calculated or assessed by 
adopting the Cifuentes Methodology (Cifuentes, 1992) which is also suggested by the International Conservation of Nature and Natural Resources (IUCN).

3.1 Physical Carrying Capacity (PCC): "PCC is the maximum number of visitors who can physically attend in a given place and time. To apply this method, it is important to consider tourist flows, the size of the area, the optimum space available for each tourist to move freely and the visiting time" (Cifuentes, 1992).

$\mathrm{PCC}=($ Size of the Area) $\times($ Area required per Tourist $) \times($ Open period (hrs/day))

3.2 Real Carrying Capacity (RCC): "RCC is the maximum permissible number of visits to a specific site, which is calculated according to the limiting factors resulting from specific conditions of that place and influence of these factors on the Physical Carrying Capacity. It is worth noting that these limiting or corrective factors are not necessarily the same for each site; and only the negative factors which hinder or affect tourism activities are considered, among which the environmental factors are usually the most important. These factors are then translated into quantitative values" (Nghi L. T., 2007).

$R C C=\operatorname{PCC} x\left(1-c f_{1}\right) x\left(1-c f_{2}\right) x \ldots . .\left(1-c f_{n}\right)$

\section{Where,}

$c f=M_{1} / M_{t} x 100$

cf is the Corrective Factor, expressed as a percentage.

$M_{1}$ is the Limiting Magnitude of the Variable; $M_{t}$ is the Total Magnitude of the Variable

\section{Results and Discussion}

As discussed in the above section, the calculation of PCC is based on the physical characteristics of the tourist destination for example, the size of the open public areas, average time spent by tourists, and the opening hours in a day. Calculation of RCC is based on the climatic and natural conditions of the tourist destinations. Parameters to calculate the RCC will vary from place to place according to the climatic conditions. In this paper, rainy 
days, natural disturbances and weather conditions are the parameters taken for the calculation for RCC.

Table 1 PCC and RCC of tourist destinations in Dakshina Kannada District

\begin{tabular}{clcc}
\hline $\begin{array}{c}\text { Sl. } \\
\text { No. }\end{array}$ & \multicolumn{1}{c}{ Tourist Destination } & PCC (Yearly) & RCC (Yearly) \\
\hline 1 & Sultan Battery & 25443420 & 12898081 \\
2 & Shree Gokarnanth Temple & 11440925 & 5799770 \\
3 & Panambur Beach & 29200000 & 14802411 \\
4 & Thannirubhavi Beach & 15595720 & 7905968 \\
5 & Pilikulanisargadama & 32633920 & 16543174 \\
6 & Bappanadu Temple & 18127725 & 9189522 \\
7 & Savirakambadabasadi & 9844050 & 4990263 \\
8 & Gommateshawara Statue & 5176187 & 3485519 \\
9 & Dharmastala & 31939325 & 21507169 \\
10 & Kukkesubramanya Temple & 9822150 & 4930611 \\
11 & Mahalingeshwara Temple & 8555600 & 4461560 \\
12 & Sadashiva Temple & 3175500 & 2018505 \\
\hline
\end{tabular}

Table 1 shows the Physical and the Real Carrying Capacities per year of all tourist locations in Dakshina Kannada District, Karnataka. If we observe the relation between the Real and the Physical Carrying Capacities of locations, Real Carrying Capacity will be less than the Physical Carrying Capacity. This is because the Physical Carrying Capacity is estimated by only the physical characteristics of the locations. But in calculation, the Real Carrying Capacity also includes the climatic and natural conditions besides the physical characteristics.

Shree Gokarnanth Temple Calculation:

Area that has been taken for the calculation: 6269 sq.m.

Every visitor needs 1 sq.m. of the separation at any given development. 
Shree Gokarnanth Temple stays open to visitors for 15 hours every day in the whole year.

An average time of 3 hours is sufficient for a tourist to visit Shree Gokarnanth Temple.

PCC $=$ Size of the Area $X$ Area required per Tourist $X$ Open Period (hrs/day)

$=6269 \times 1 \times 5$

$=31345$ per Day

$=31345 \times 365$ Visitors per Year

$=11440925$ Visitors per Year

Correction factors taken is rain, natural disturbances, weather condition

Rainy days $=135$

Natural Disturbances $=30$

Weather Condition $=45$

Cf1 $=135 / 365=0.370$

$\mathrm{Cf} 2=30 / 365=0.082$

Cf3 $=40 / 365=0.123$

$=15890$ per Day

$=15890 \times 365$ Tourists per Year

$=5799770$ Tourists per Year

The box shows the detailed calculations of the Physical and Real Carrying Capacities of Shree Gokarnanth Temple. As discussed in the literature and in the methodology section, the indicators considered for estimation of the Real Carrying Capacities are rainy days, natural disturbances, and weather conditions. As Shree Gokarnanth Temple is in Mangalore taluk, the number of rainy days taken per year was 135 days, number of natural disturbances (in days) taken per year was 30, and the number of days per year that weather conditions are unusual for tourism was 45 days. $\mathrm{Cf}_{1}$, 
$\mathrm{Cf}_{2}, \mathrm{Cf}_{3}$ are the ratios of Limiting Magnitude of Variables to Total Magnitude of the Variables.

\section{Conclusion}

The Dakshina Kannada District is enriched with natural and ecoclimatic conditions along with the healing powers of the Western Ghats which incredibly makes a difference to the tourism sector in the district. Real Carrying Capacity and Physical Carrying Capacity figures show that the tourist destinations are not fully utilised as the present number of tourists do not really reach up to the estimated Carrying Capacity of the tourist destination.

The purpose of this research study was to outline the theory and practice of Tourism Carrying Capacity Assessment and its significance as a management tool for the tourist locations in Dakshina Kannada District. From the figures of Real Carrying Capacity, we understand that the actual numbers of tourists are farther away from the maximum figures allowed. These values will help guide the government and tourism authorities to initiate necessary development activities in all tourist destinations.

The Carrying Capacity Assessment of tourist destinations will also help in Reverse Engineering Process of the tourist destinations. That is, the authorities will receive prior knowledge about the damages that could be caused to the natural eco-sensitive tourist destinations due to mass tourism and over-crowding. Finally, Carrying Capacity Assessment should be promoted as a part of the Sustainable Tourism Development of nature-based destinations in the Dakshina Kannada District for the purpose of providing better experience to the tourists.

\section{References}

Attallah, N. F. (2015). The estimation of physical and real carrying capacity with application on Egypt's tourist sites. Journal of Tourism Research, 12, 65-82.

Cifuentes. (1992). Determinacion de Capacidad de cargeturistica en Areas Protegidas. Turrialba, Costa Rica: CATIE

Clark. (1996). Coastal Zone Management Handbook. Boca Raton, Florida. CRC Press, Inc. 
Coccossis, H., \& Mexa, A. (2004). Tourism carrying capacity: methodological considerations. In The challenge of tourism carrying capacity assessment: Theory and practice (pp. 55-90). England: Ashgate.

Manning, R. E. (2002, January). How much is too much? Carrying capacity of national parks and protected areas. In Monitoring and management of visitor flows in recreational and protected areas. conference proceedings (pp. 306-313).

Tran, N., Nguyen, T. L., Nguyen, D. T., Dang, M., \& Dinh, X. T. (2007). Tourism carrying capacity assessment for Phong Nha-Ke Bang and Dong Hoi, Quang Binh Province. VNU Journal of Science, Earth Sciences, 23, 80-87.

Pazienza, P. (2004). A multidimensional tourism carrying capacity model: an empirical approach. In XIII International Leisure and TOurism Symposium ESADE. ESADE Business School.

Shetty. (2014). Dakshina Kannada District Human Development Report. Mangalore: Dakshina Kannada zilla panchayat, Government of Karnataka.

Turner, B. (1997). Environmental carrying capacity and tourism development in the Maldives and Nepal. Environmental Conservation, 316-325.

WTO. (1999). Global code of ethics for tourism. Santiago. WTO. 